\title{
A Conexão Ministerial: governo de coalizão e viés partidário na alocação de emendas parlamentares ao orçamento (2004-2010) ${ }^{1}$
}

\author{
Mariana Batista* I Universidade Federal de Pernambuco
}

\begin{abstract}
Resumo. 0s ministros influenciam a alocação de recursos pelo Executivo Federal? 0 presente trabalho discute em que medida o poder dentro do Executivo é compartilhado entre o presidente e os partidos que formam a coalizão governativa, analisando a alocação de recursos pelo Executivo Federal. 0 foco específico está nas emendas parlamentares ao orçamento federal no período de 2004 a 2010 . Busca-se identificar se o controle de ministérios pelos partidos da coalizão significa um canal privilegiado para os membros dos partidos da coalizão. A hipótese central é que ser membro do partido do ministro ao qual o recurso está vinculado aumenta a chance de liberação da emenda parlamentar. 0s resultados indicam que parlamentares do mesmo partido do ministro são beneficiados na alocação de emendas. Contudo, o viés partidário não é extremo, de forma que o partido do presidente é igualmente beneficiado e os demais partidos da coalizão também recebem recursos, indicando a atuação de mecanismos de coordenação pela Presidência da República.
\end{abstract}

Palavras-Chave. Presidencialismo, governo de coalizão, relação executivo-legislativo, emendas orçamentárias.

\section{Introdução}

No presidencialismo de coalizão o apoio político dos partidos da base no Congresso é estabelecido a partir da distribuição de pastas ministeriais para os diferentes partidos que compõem a coalizão governativa (Amorim Neto, 2001). Com o apoio da coalizão o presidente é capaz de aprovar sua agenda legislativa e manter a governabilidade. Este é um ponto suficientemente enfatizado na literatura (Figueiredo e Limongi, 2001). Contudo, pouco ainda se sabe sobre o funcionamento do presidencialismo de coalizão sob a perspectiva do Poder Executivo.

0 sistema presidencialista apresenta o presidente como chefe absoluto e responsável pelo governo. Contudo, com a distribuição de posições no gabinete para os partidos da coalizão, cada ministro tem controle sobre uma pasta específica, significando em alguma medida influência sobre as decisões tomadas na área. Segundo Martin e Vanberg (2012), tais governos se tornam mais complexos e geram maiores custos de coordenação, tendo em vista que os diferentes partidos governam juntos, mas disputam eleições separadamente. Nesse sentido, os ministros representam partidos com posições políticas e preferências próprias. 0 presente trabalho parte do pressuposto de que há processos internos de delegação e de coordenação que fazem com que a teoria do Poder Executivo como ator unitário, identificado exclusivamente como o presidente, não seja apropriada para o entendimento dos governos de coalizão brasileiros.

Neste sentido, como se dá a relação entre o presidente e os ministros no processo decisório de um governo multipartidário? Qual a influência da coalizão nas decisões do Executivo? Essas questões se tornam ainda mais importantes considerando a dominância legislativa e os fortes poderes orçamentários do Executivo federal brasileiro. 0 presente trabalho foca na participação da coalizão na alocação de recursos do Poder Executivo. 0 foco específico está nas emendas parlamentares, já que esta é a forma mais diretamente observável de participação dos parlamentares na formulação do orçamento 
brasileiro. Tais emendas podem ser vistas como o principal mecanismo de obtenção de recursos pelos parlamentares para influenciar os eleitores, numa estratégia de sobrevivência política (Pereira e Rennó, 2001; Pereira e Mueller, 2003). Nesse sentido, são recursos valorizados pelos parlamentares. Qual o papel dos ministros na execução de tal estratégia?

Assumindo que a formação de governos de coalizão significa os partidos políticos no processo decisório do Poder Executivo, a análise das emendas parlamentares permite identificar se há variação na alocação de tais recursos de acordo com a distribuição de pastas ministeriais específicas entre os membros da coalizão. Busca-se aqui identificar se a alocação de emendas parlamentares é feita de forma a beneficiar o partido do ministro setorial ou mecanismos de coordenação impostos pelo presidente estão presentes de forma a impedir a autonomia ministerial.

Testando o argumento de Laver e Shepsle (1990), a hipótese é a de que um viés partidário pode ser observado na alocação de emendas parlamentares, de forma que os ministérios podem ser vistos como um canal privilegiado para os membros dos partidos da coalizão no processo decisório do Poder Executivo. Dito de outra forma, os parlamentares valorizam emendas parlamentares e os ministros são representantes partidários, de forma que se tiverem autonomia para tanto, buscarão beneficiar os membros do seu próprio partido.

0 artigo está organizado da seguinte forma. A próxima seção se dedica à discussão sobre governos de coalizão e desenvolve o argumento sobre o papel dos ministros na alocação de recursos orçamentários pelo Poder Executivo. Em seguida, o processo orçamentário brasileiro é analisado. Na quarta seção os dados, variáveis, métodos e os resultados sobre o viés partidário na alocação de emendas parlamentares pelos ministérios no período de 2004 a 2010 são analisados. Por último a conclusão.

\section{Governos de Coalizão: formação, governança e implicações para 0 presidencialismo brasileiro}

Um tema bastante tradicional na análise sobre sistemas parlamentaristas está na formação e no funcionamento de governos de coalizão. Um trabatho pioneiro que se tornou clássico é The Theory of Political Coalitions de William Riker (Riker, 1962). Neste trabalho Riker (1962) lança o argumento até então contraintuitivo de que na barganha política para a formação de um governo de coalizão, os partidos não maximizam cadeiras, isto é, não buscam a formação de um governo com o maior número de cadeiras legislativas, mas sim buscam a formação de um governo que controle apenas o número suficiente de cadeiras para ganhar. Esse é o critério da coalizão mínima vencedora, que se tornou dominante no debate.
A partir deste princípio, trabalhos foram feitos no sentido de entender os determinantes da formação, composição e tamanho das coalizões. 0 foco está na formação do governo com base na barganha entre atores racionais maximizando a sua participação na distribuição do "prêmio". 0 prêmio em questão é o governo, que pode ser subdividido em subunidades - os ministérios - e distribuído entre os membros da coalizão vencedora. 0 argumento dominante é o de que os partidos na coalizão demandarão participação no governo proporcional ao seu tamanho, no que ficou conhecido como Lei de Gamson: "Any participant will expect others to demand from a coalition a share of the payoff proportional to the amount of resources which each contribute to a coalition" (Gamson, 1961: 376).

Os modelos de formação de governo orientados pelo princípio do tamanho e o argumento da demanda proporcional de participação no governo estabelece implicitamente o que é conhecido como o argumento office-seeking. Isto é, o prêmio a ser dividido são posições no gabinete e isto é tudo a ser considerado no jogo de formação da coalizão. Alguns trabalhos posteriores passaram a enfatizar o aspecto ideológico na formação de governos de coalizão. Isto é, algumas coalizões são mais prováveis do que outras e isto acontece devido a razões de proximidade ideológica entre os futuros parceiros. Aqui a ênfase é na busca por cargos, porém, esses cargos seriam um instrumento para a implementação de políticas. Como após a formação da coalizão é esperado que os membros governem juntos, considerações acerca da policy-position dos atores são de importância (Axelrod, 1970; DeSwaan, 1973).

Pensar no quê acontece após a formação do governo e como os partidos de fato governam representou a transição do foco exclusivo na formação da coalizão para as análises sobre a governança das coalizões. Nas palavras de Laver e Shepsle (1990): “discussions of government coalitions have concentrated almost exclusively on the fact that they are coalitions and more or less ignored the fact that they are also governments. Little attention has been devoted to what happens after a government has been formed" (Laver e Shepsle, 1990: 873). Nas análises sobre governança o debate gira em torno de como as decisões são tomadas, quais atores influenciam as decisões e como a divisão do trabalho afeta as políticas implementadas pelo governo.

Laver e Shepsle (1990) construíram o argumento dominante sobre a divisão do trabalho em governos de coalizão em sistemas parlamentaristas. Os autores analisam as barganhas da coalizão sobre alternativas críveis de alocação de portfólios. 0 argumento básico é o de que a autonomia ministerial sobre o ministério específico e a implementação das preferências do partido que controla o ministério é a única alternativa crível de formação do governo, já que um partido não pode se comprometer a implementar políticas que se afastem da sua preferência. Nesse sentido, os ministros possuem autonomia na 
condução das decisões de seu ministério e por isso é esperado que implementem a decisão mais próxima de suas preferências. Nas palavras dos autores:

"Division of labor within a cabinet means that most ministers are assigned particular policy jurisdictions, or 'portfolios'. This gives a minister the job of initiating and implementing policy within a particular field. The resources commanded by a minister to facilitate this - typically control over a government department - give considerable de facto power over policy outputs in the minister's jurisdiction. (...) This characterization of the workings of the division-of-labor cabinet system should lead actors to forecast that jurisdiction-specific policy outputs will tend towards those preferred by the party of the relevant minister. This means that a proposal that promises to enact the preferred policy position of the person (party) nominated for each relevant portfolio is credible in the sense that it depends only on giving ministers the power to do what they expressly want to do. Any proposal promising that a minister with wide-ranging power over the relevant policy jurisdiction will act against expressed preferences is less credible" (Laver e Shepsle 1990: 874).

Neste argumento que ficou conhecido como "portfolio allocation", os autores propõem um modelo de divisão do trabalho sob governo de coalizão no qual os ministros possuem total autonomia decisória sobre a área específica que controlam. Nesse sentido, a distribuição específica de ministérios e o posicionamento ideológico dos partidos se tornam fundamentais para entender não só a formação da coalizão, mas também os resultados do governo. Sobre o "governo ministerial", Laver e Shepsle (1994) afirmam:

“[Ministerial government] implies a powerful executive in which individual ministers, by virtue of their positions as the political heads of the major departments of state, are able to have a significant impact on policy in areas that fall under their jurisdiction. This entails a division-and-specialization-of-labor arrangement in which effective policy of any government depends upon the allocation of cabinet portfolios between politicians. A different allocation implies a different policy profile for the cabinet, and changes in portfolio allocations signal changes in government policy" (Laver e Shepsle, 1994: 8)

Apesar da dominância de tal argumento na literatura sobre governos de coalizão em sistemas parlamentaristas, uma série de trabalhos vem colocando em discussão o pressuposto da total autonomia dos ministérios. Segundo Thies (2001), governos implicam delegação de poderes e governos de coalizão implicam relações de delegação ainda mais complexas, tendo em vista que a delegação é interpartidária e não intrapartidária como em governos de partido único.

Dessa forma, há duas opções para a governança da coalizão: a autonomia ministerial, que o autor ar- gumenta ser uma opção subótima, devido à incerteza quanto às decisões tomadas pelo ministério, e a alternativa de "administrar" a delegação aos ministros. Tal administração de coalizões multipartidárias pode ser feita através do desenho institucional centralizado, como forma de supervisionar as decisões dos ministérios, ou, principalmente, a indicação de "ministros-júnior" de outro partido que não o do ministro, como um contraponto ao controle absoluto do ministro e também como uma fonte de informação alternativa para os parceiros da coalizão (Thies, 2001).

Martin e Vanberg $(2004 ; 2011)$ apontam o papel do parlamento nas democracias parlamentaristas como uma arena decisória alternativa, na qual os conflitos não resolvidos ou a assimetria informacional entre os parceiros da coalizão tem uma nova oportunidade de discussão e revisão dos acordos. As bancadas dos partidos membros da coalizão podem observar as decisões de ministérios controlados por outros partidos e assim manter as decisões do governo mais próximas das preferências da coalizão como um todo e não só to partido que controla o ministério específico (Martin e Vanberg, 2004; 2011).

A primazia do ministro na área específica que controla ainda é aceita. Contudo, formas de controle mútuo são desenhadas como forma de manter o governo de fato da coalizão e não departamentalizado em unidades autônomas e desconectadas.

Trabalhos empíricos vêm sendo feitos no sentido de testar a capacidade preditiva do modelo de autonomia ministerial e a sua alternativa com base na coordenação e controle mútuo no gabinete. A estratégia proposta por Laver e Shepsle (1994) é contrastar os modelos de tomada de decisão com base numa variável dependente específica. Isto é, modelos de gabinete são traçados e busca-se identificar qual modelo explica a variação nas políticas adotadas pelo governo. Segundo Laver e Shepsle (1994), há seis modelos possíveis: o governo burocrático, no qual a composição da burocracia determina as políticas adotadas; o governo legislativo, no qual todas as decisões sobre políticas são tomadas pela legislatura; o governo do primeiro ministro, no qual as preferências do primeiro ministro determinam as políticas adotadas; o governo do partido, partidos bem organizados e disciplinados ao controlar o governo controlam as decisões políticas tomadas; governo do gabinete, as decisões são tomadas coletivamente; por último, o governo ministerial, no qual as políticas adotadas por cada ministério refletem as preferências do ministro que lidera o departamento (Laver e Shepsle, 1994).

Uma forma de testar o papel dos ministérios nas decisões tomadas pelo governo é identificar as preferências dos ministros setoriais e avaliar se as políticas adotadas pelo governo na área específica refletem tais preferências ou não. No primeiro caso, o teste mostrará evidência a favor da autonomia ministerial, no segundo formas de coordenação e controle mútuo estão em ação e devem ser analisadas. 
0 objetivo do presente trabalho é se basear em tais testes como uma forma de identificar a participação dos ministérios na tomada de decisão e alocação de recursos pelo Poder Executivo brasileiro. Contudo, como utilizar esse conhecimento acumulado sobre governos de coalizão em sistemas parlamentaristas para entender o caso brasileiro? "Presidencialismo e parlamentarismo são, de fato, diferentes e as instituições claramente criam incentivos" (Cheibub, Przeworski e Saiegh, 2002: 188). Uma séria de regras marca as diferenças institucionais entre presidencialismo e parlamentarismo, dentre elas a eleição direta para o chefe do Poder Executivo, a sua autonomia frente o Legislativo, a existência de mandato fixo e independência nas indicações para composição do governo (Stepan, 1990).

No presidencialismo brasileiro o presidente tem autonomia na condução das decisões do governo e pode ainda modificar a configuração de seu ministério sem necessidade de aprovação pelo Legislativo. Nesse sentido, algo razoável a ser assumido é que as políticas respondam às preferências do presidente. Contudo, qual seria então o incentivo para um partido integrar a coalizão se não tem nenhuma perspectiva de influenciar as decisões do governo?

0 argumento aqui desenvolvido é o de que o presidencialismo de coalizão representa uma barganha entre o presidente e os partidos de coalizão, na qual o presente busca apoio político para a sua agenda legislativa e os partidos em contrapartida buscam influência sobre as decisões governamentais. Uma vez no controle de um ministério, o ministro tem por objetivo influenciar as decisões de modo a beneficiar o seu próprio partido e assim extrair rendas da participação no governo. A questão que se impõe é se o ministro consegue impor a sua preferência ou se o presidente é capaz de manter o governo sob controle, mantendo as decisões mais próximas do seu próprio interesse.

Partindo da estratégia proposta por Laver e Shepsle (1994), busca-se avaliar se as políticas adotadas pelo governo refletem as preferências do presidente ou se a distribuição de ministérios é uma variável relevante para entender as decisões do governo. Para tanto, é preciso identificar as preferências do presidente e dos ministros e observar uma determinada decisão do governo como forma de identificar a sua ligação com os ministérios. A estratégia aqui utilizada é a de analisar a distribuição de emendas parlamentares. 0 foco é na participação da coalizão na alocação de recursos do Poder Executivo.

Emendas parlamentares são vistas como a principal forma de participação dos parlamentares na alocação de recursos do orçamento federal. Com o forte controle exercido pelo Executivo, a inclusão de interesses dos parlamentares pode ser feita diretamente apenas através de emendas à proposta apresentada pelo Executivo. Segundo o debate recente, emendas parlamentares são valorizadas pelos parlamentares por possibilitarem uma forma de transferir recursos para o seu eleitorado e assim conquistar votos num sistema eleitoral que incentiva a ligação personalista entre representante e representado (Pereira e Rennó, 2001; Pereira e Mueller, 2003).

Ademais, as emendas parlamentares são vinculadas a ministérios específicos. Partindo do objetivo de identificar a participação dos ministros na alocação de recursos, assume-se que os ministros preferem alocar recursos para o seu próprio partido, de modo que a autonomia ministerial deve se apresentar como um viés partidário na alocação de emendas parlamentares, favorecendo o partido do ministro. Os ministérios serviriam como um canal privilegiado para os membros do partido no governo, da mesma forma que o ministro representa o apoio do seu partido no Legislativo.

A próxima seção analisa o desenho institucional do Executivo, os dados de emendas parlamentares ao orçamento e a metodologia utilizada para estimar 0 efeito de controlar o ministério sobre a execução das emendas apresentadas no período de 2004 a 2010.

\section{Desenho Institucional do Executivo: regras e procedimentos do processo de alocação do orçamento}

No processo orçamentário brasileiro estão previsto três estágios: a elaboração da peça orçamentária pelo Poder Executivo, a discussão, modificação e aprovação pelo Legislativo e a execução dos gastos novamente pelo Executivo. Como pode ser visto, o poder de agenda e a palavra final ou a "chave do cofre" estão com o Poder Executivo. Por essa razão, "there are strong reasons to believe that the president plays a central role in determining which jurisdictions get what, when, and how" (Berry, Burden e Howell, 2010: 783).

De acordo com Berry, Burden e Howell (2010), a literatura empírica sobre política distributiva tem sido "legislature centric" e o Executivo quando aparece nas análises é identificado como um veto player. Contudo, o papel do Executivo é muito mais amplo do que o simples veto. Durante a formulação, e ainda mais importante, durante a implementação do orçamento o Executivo tem amplas oportunidades de afetar a distribuição de recursos de acordo com suas preferências políticas Berry, Burden e Howell, 2010). Dessa forma, para entender a atuação do governo nos gastos públicos e a participação dos atores políticos na alocação de recursos é preciso olhar também para o funcionamento interno do Executivo.

0 processo orçamentário no Brasil é dividido em três peças legislativas principais de iniciativa exclusiva do Presidente: o plano plurianual, a lei de diretrizes orçamentárias e a lei orçamentária anual. 0 plano plurianual (PPA) estabelece de forma regionalizada as diretrizes, objetivos e metas da administração pública federal, contendo os programas de trabalho a serem realizados nos quatro anos seguintes. Constitui-se no grande instrumento de planejamento que orienta a formulação dos orçamentos anuais no período que 
compreende. A lei de diretrizes orçamentárias (LDO) estabelece, com base no PPA, as metas e prioridades que deverão ser observadas na formulação do orçamento. Com base no planejamento para quatro anos do PPA, a LDO estabelece as prioridades. Por último, a lei orçamentária anual (LOA) estabelece a programação financeira do próximo ano fiscal de forma consolidada, indicando a fonte de receita e previsão de despesa para o orçamento fiscal, o orçamento de investimento das empresas e o de seguridade social. A LOA apresenta o impacto regionalizado dos gastos previstos e tem por objetivo expresso a redução das desigualdades regionais. Na prática a LOA estabelece restrições sobre os gastos no ano fiscal, uma vez que é vedado o início de programas não incluídos na lei e a realização de despesas que excedam os créditos orçamentários (Brasil, 1988).

A Constituição Federal de 1988 classifica os orçamentos anuais como leis de iniciativa do Poder Executivo, porém, não dispõe sobre as regras de formulação do projeto dentro do Executivo, garantindo poderes discricionários para o presidente, que pode organizar o processo e o papel dos atores internamente. Com base nos manuais técnicos do orçamento, documento organizado pelo Ministério do Planejamento/Secretaria de Orçamento Federal, é possivel entender o processo interno de formulação das leis orçamentárias anuais no Brasil.

0 órgão central do sistema de planejamento federal é a Secretaria de Orçamento Federal (SOF), do Ministério do Planejamento. Este órgão é responsável por receber e consolidar as propostas dos órgãos setoriais, compatibilizando-as entre si e com as metas e objetivos do governo como um todo. As unidades de orçamento dos ministérios e da Casa Civil se constituem em órgãos setoriais. As unidades orçamentárias são responsáveis pela programação e execução orçamentária (Lei 10.180/2001; Ministério do Planejamento, 2004; 2012).

A figura abaixo apresenta o processo orçamentário, com ênfase no papel desempenhado por cada um desses atores nos diferentes estágios de formulação da lei Orçamentária Anual.

Figura 1. Processo de Formulação da Lei Orçamentária Anual

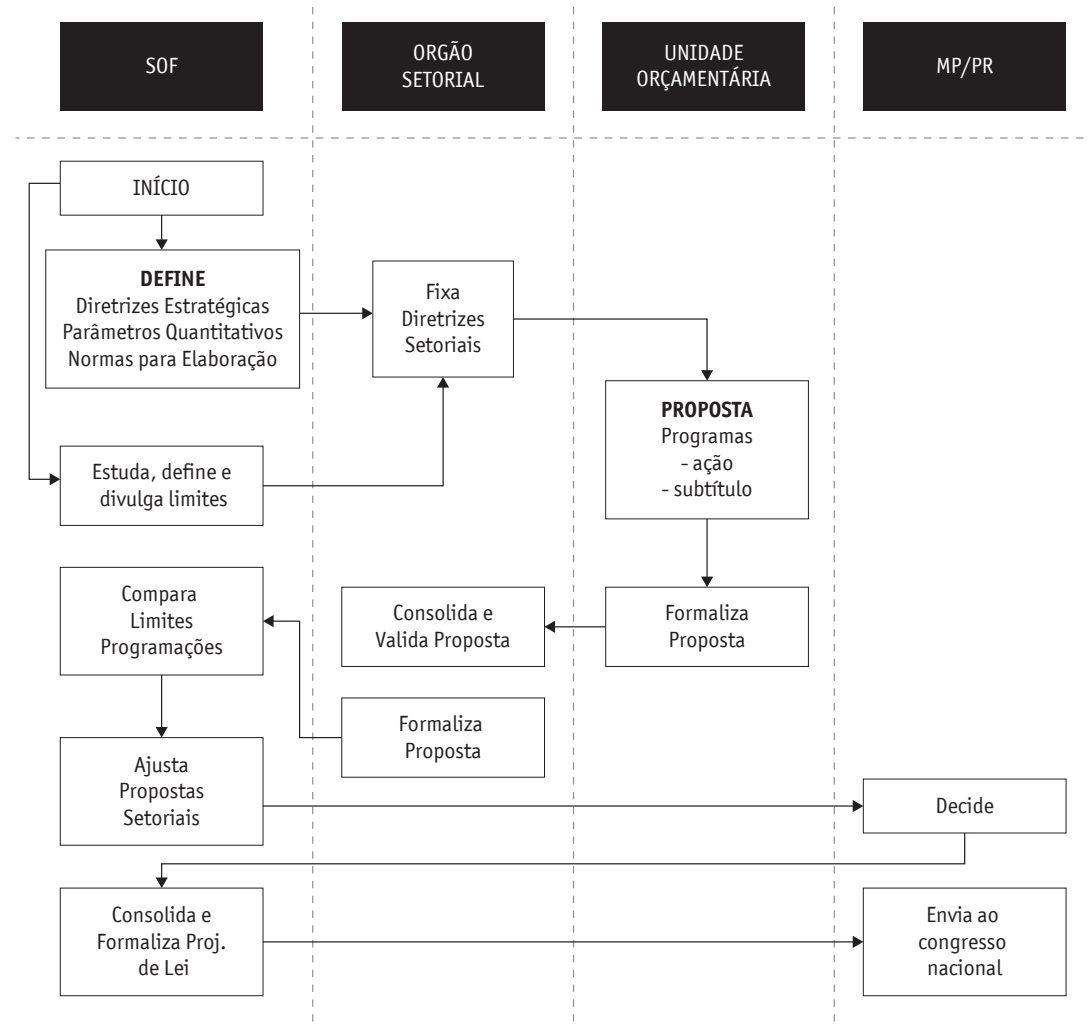

Fonte: Ministério do Planejamento (2012).

0 processo de formulação da peça orçamentária tem seu início no órgão central - a SOF - que estabelece as previsões de receita e limites de gasto por unidade. A definição das diretrizes macroeconômicas do orçamento conta com participação da assessoria econômica do Ministério do Planejamento, do Ministério da Fazenda, da Casa Civil e dos órgãos setoriais. A definição e divulgação dos limites para as propostas setoriais conta com o respaldo da Casa Civil como representante da Presidência. De acordo com Alston et all (2009), "it is at this stage that the trickiest negotiations occur within the executive branch itself, with each part trying to enlarge its own budget and the treasury trying to hold back their demands" (Alston et all, 2009: 71). Em seguida os órgãos setoriais estabelecem as diretrizes para cada unidade e as unidades orçamentárias formulam os programas de trabalho com base nas limitações pré-estabelecidas. Formalizadas as propostas setoriais, a SOF ajusta as propostas e envia 
para o órgão central do Poder Executivo, a Presidência da República, assistida pelo Ministério do Planejamento, para decisão quanto ao seu conteúdo.

Uma vez formulada a proposta, o projeto é enviado ao Congresso em apreciação unicameral regida pelo regimento comum. Mesmo se tratando de um projeto de lei ordinária, a LOA apresenta um rito especial devido a natureza de sua matéria orçamentária. A apreciação é feita por uma comissão mista composta de 40 membros, 30 deputados e 10 senadores, respeitando o critério da proporcionalidade partidária. 0 projeto é dividido em áreas temáticas, a cargo de relatores setoriais.

0 principal mecanismo de atuação dos parlamentares sobre o orçamento é através das emendas parlamentares. Através das emendas "os parlamentares podem opinar ou influir na alocação de recursos públicos em função de compromissos políticos que assumiram durante seu mandato, tanto junto aos estados e municípios quanto a instituições. Tais emendas podem acrescentar, suprimir ou modificar determinados itens (rubricas) do projeto de lei orçamentária enviado pelo Executivo" (Senado, 2013). As emendas podem ser individuais, de bancada (estaduais) ou de comissão e obedecem atualmente os seguintes limites: 25 emendas individuais por parlamentar com base no limite fixado no parecer preliminar, entre $4 \mathrm{e}$ 8 emendas para as comissões e as bancadas estaduais podem apresentar até 23 emendas .

A proposição de emendas é limitada por uma série de restrições. As emendas que propõem acréscimo ou inclusão de despesas só podem ser aprovadas se estiverem incluídas no PPA e na LDO e a partir da indicação da fonte de recursos necessários para sua execução. Dessa forma, os parlamentares incluem suas propostas dentro dos limites e dos programas estabelecidos anteriormente. Usualmente as emendas parlamentares são vinculadas aos programas de trabalho dos ministérios, não sendo tão facilmente dissociadas dos programas do governo. Isto é, os parlamentares não promovem novos gastos ou novas políticas públicas, mas sim incluem suas preferências de alocação, principalmente quanto a distribuição geográfica dos recursos, na estrutura programática estabelecida nos ministérios.
Uma vez aprovada, a lei orçamentária é enviada ao Executivo para sanção presidencial. Após a sanção tem início o processo de execução. Este processo tem como atores principais no âmbito do Executivo Federal o ministério do planejamento (MP), o ministério da fazenda (MF) e os ministérios gestores. A execução orçamentária, definida como a utilização dos créditos consignados na LOA, tem sua liderança no MP, e a execução financeira, que representa a utilização dos recursos financeiros, é liderada pelo MF através da Secretaria do Tesouro Nacional (STN).

0 processo de execução tem início na programação de desembolso, que tem por objetivo ajustar o ritmo de execução do orçamento ao fluxo provável de recursos. Isto é, uma vez aprovada a LOA o Executivo adapta os objetivos da lei ao ritmo específico de implementação dos gastos de acordo com a previsão de recursos disponíveis. Essa programação é realizada até 30 dias após a sanção da LOA através de decreto do Executivo. Esse decreto inicial estabelece os valores autorizados para movimentação e empenho e valores mensais autorizados para pagamento. Ou seja, logo após a LOA o Executivo adapta a programação orçamentária, e apresenta no decreto inicial a diferença entre os valores fixados na lei e os valores liberados para movimentação e empenho. Essa diferença é chamada de contingenciamento e reflete a atuação direta do Executivo na redistribuição de recursos entre as suas unidades .

Além dessa limitação inicial, o Executivo estabelece ainda cotas financeiras mensais para os ministérios, e é formulada em conjunto entre o MP e o MF. Essas cotas tem por objetivo manter o equilíbrio entre os gastos e a arrecadação de forma continuada e buscam "assegurar a liberação automática e oportuna dos recursos necessários à execução dos programas anuais de trabalho". Desta forma se teria a flexibilidade da implementação descentralizada dos gastos nos ministérios aliada ao controle centralizado sobre o ritmo dos gastos durante o ano fiscal. 0 processo de execução financeira prevê a liberação dos recursos financeiros na forma de liberações mensais após solicitação e aprovação das propostas financeiras das unidades gestoras. A figura abaixo apresenta o processo de execução orçamentária e financeira no Executivo Federal.

Figura 2. Processo de Execução Orçamentária/Financeira no Executivo Federal

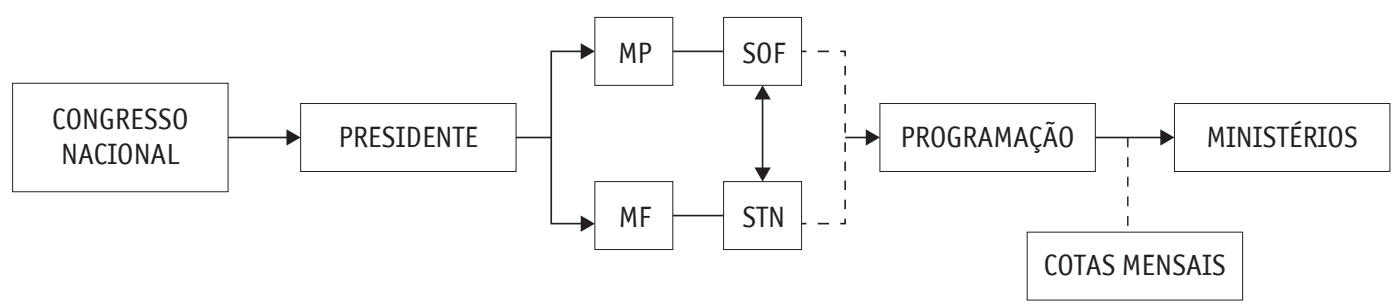

Fonte: elaboração própria com base na legislação citada. 
Como pôde ser visto, a participação direta dos parlamentares no sentido de alocar recursos para o seu eleitorado se restringe às emendas parlamentares. $\mathrm{Na}$ prática, tais emendas acabam restringindo-se principalmente aos recursos de investimento das unidades orçamentárias, no caso aqui analisado, os ministérios. Como o orçamento é autorizativo e não impositivo, o Executivo tem a prerrogativa de contingenciar dotações e reter liberações financeiras, controlando o direcionamento da alocação de recursos e também o timming das liberações. Nesse ponto poderia se esperar a autonomia dos ministros na execução das emendas parlamentares vinculadas ao seu orçamento. Contudo, a atuação de um dos órgãos da presidência se torna relevante no que concerne às emendas parlamentares.

A Secretaria de Relações Institucionais da Presidência da República (SRI) é um órgão de apoio direto ao presidente, contando na estrutura da Presidência da República. Compete à Secretaria de Relações Institucionais assistir ao presidente na coordenação política do governo, na condução da relação do governo com o Congresso Nacional e partidos políticos e também na relação com estados e municípios (Lei 10.683/2003). Nessa interlocução entre o Executivo e o Legislativo a SRI se torna fundamental quando consideramos a sua prerrogativa de "acompanhar, apoiar e, quando couber, recomendar medidas aos órgãos e entidades da administração pública federal quanto à execução das emendas parlamentares, constantes da Lei Orçamentária Anual, e sua adequação aos critérios técnicos e de compatibilização com a ação governamental" (Decreto 6.207, 2007). Nesse sentido, a SRI acaba assumindo o papel de receber as demandas dos parlamentares para a execução de suas emendas aprovadas no orçamento, pressionando os ministérios na liberação. Dessa forma, mesmo não sendo considerada diretamente na estrutura do processo orçamentário, a SRI pode desempenhar papel fundamental, limitando a autonomia dos ministérios, buscando manter a liberação das emendas parlamentares mais próxima dos interesses do presidente.

Tendo em mente a prerrogativa dos ministros de orientar a execução orçamentária do ministério que chefia e essa estrutura de centralização das decisões de liberação de recursos num órgão da presidência, os ministério são capazes de alocar os recursos de forma a beneficiar o seu próprio partido ou a centralização na presidência reduz a autonomia ministerial mantendo as decisões do governo de acordo com as preferências do presidente? A próxima seção apresenta os dados, a metodologia e os resultados do teste da hipótese de que há um viés partidário na alocação de emendas no sentido de beneficiar o partido do ministro.

\section{Conexão Ministerial na Alocação do Orçamento? Dados, métodos e resultados}

Para compreender o papel dos ministérios na alocação de recursos do Executivo Federal foram analisadas as emendas parlamentares aprovadas ao orçamento federal e a execução de tais emendas. 0 período analisado é de 2004 a 2010, incluindo assim os dois governos de Luiz Inácio Lula da Silva, permitindo variação de coalizão, de composição partidária dos ministérios e do ciclo eleitoral. A comparação com os governos de Fernando Henrique Cardoso (19952002) não foi possível devido à indisponibilidade de dados para o período no sistema consultado.

A análise tem por base a identificação do partido dos autores das emendas ao orçamento, o ministério ao qual a emenda se vincula e a filiação partidária do ministro. Para as informações sobre as emendas parlamentares foi construído um banco de dados com base nas informações do Siga Brasil. 0 banco é composto por todas as emendas parlamentares ao orçamento. As informações sobre execução de emendas parlamentares somente estão disponíveis a partir de 2002. Os anos de 2002 e 2003 não foram considerados aqui por serem anos "atípicos", o último ano do governo Fernando Henrique Cardoso, e assim não seria material suficiente para generalizar para esse governo, e o primeiro ano do governo Luiz Inácio Lula da Silva, com um orçamento aprovado durante o governo anterior. Foi analisado um total de 69.952 emendas parlamentares aos orçamentos no período.

A unidade de análise é a emenda parlamentar. 0 foco está na execução ou não da emenda, consistindo numa variável de resposta qualitativa binária. $\mathrm{A}$ opção por trabalhar com apenas com a execução ou não da emenda e não com a taxa de execução vem do problema de desagregar o valor executado que se refere estritamente à emenda parlamentar e os valores referentes a execução dos programas ministeriais. Esse mais facilmente observado quando o valor executado da emenda supera em muito o valor inicialmente aprovado, com taxas de execução superiores a $100 \%$, indicando que parte do valor não se refere a emenda.

Informações sobre a filiação partidária dos ministros foram disponibilizadas por Argelina Figueiredo e tem por base seu trabalho sobre os ministros do Brasil (Figueiredo, 2007). 0 objetivo aqui é identificar se o ministro beneficia o seu partido na execução das emendas parlamentares. A hipótese a ser testada é a de que quando o parlamentar e o ministro são do mesmo partido a probabilidade de execução da emenda aumenta. A tabela abaixo apresenta a distribuição dos ministérios entre os partidos da coalizão no período analisado. 
Tabela 1. Distribuição Partidária dos Ministérios - Governos Luiz Inácio Lula da Silva (2003-2010)

\begin{tabular}{|c|c|c|}
\hline \multirow[t]{2}{*}{ Ministério } & \multicolumn{2}{|c|}{ Partidos } \\
\hline & Primeiro Mandato & Segundo Mandado \\
\hline Ministério da Agricultura, Pecuária e Abastecimento & SFP & SFP - PMDB - PMDB \\
\hline Ministério da Assistência Social & PT & - \\
\hline Ministério da Ciência e Tecnologia & PSB - PSB & SFP \\
\hline Ministério da Cultura & PV & $S F P-P V$ \\
\hline Ministério da Defesa & $S F P-P L-S F P-P L-P T$ & PT - PMDB \\
\hline Ministério da Educação & PT - PT - PT & PT \\
\hline Ministério da Fazenda & PT - PT & PT \\
\hline Ministério da Integração Nacional & PPS - PSB & PSB - PMDB - PMDB \\
\hline Ministério da Justiça & PT & PT - PT \\
\hline Ministério da Previdência Social & PT - PMDB - PMDB - SFP & SFP - PT - PT - PT \\
\hline Ministério da Saúde & PT - PMDB - PMDB & PMDB - PMDB \\
\hline Ministério das Cidades & PT - PP & PP \\
\hline Ministério das Comunicações & PDT - PMDB - PMDB & PMDB \\
\hline Ministério das Minas e Energia & PT - PMDB & PMDB - PMDB \\
\hline Ministério das Relações Exteriores & SFP & SFP \\
\hline Ministério do Desenvolvimento Agrário & PT - PT & PT \\
\hline Ministério do Desenvolvimento Social e Combate à Fome & PT & PT \\
\hline Ministério do Desenvolvimento, Indústria e Comércio Exterior & SFP & SFP - SFP \\
\hline Ministério do Esporte & $P C d o B-P C d o B$ & PCdoB \\
\hline Ministério do Meio Ambiente & PT & PT - PT \\
\hline Ministério do Planejamento, Orçamento e Gestão & PT - SFP - PT & PT \\
\hline Ministério do Trabalho e Emprego & PT - PT - PT & PT - PDT \\
\hline Ministério do Turismo & PTB & PTB - PT - PT \\
\hline Ministério dos Transportes & $P L-P L-S F P$ & SFP - PR \\
\hline Ministério da Pesca e Aquicultura & - & PT \\
\hline
\end{tabular}

Fonte: elaboração própria com base no banco de dados de Figueiredo (2007).

A tabela 1 apresenta a composição dos ministérios nos governos de Luiz Inácio Lula da Silva. Podemos notar alguns aspectos interessantes na composição das coalizões formadas nos dois governos considerados: a dominância do partido do presidente na composição dos ministérios é clara, mesmo considerando o tamanho das coalizões formadas, chegando a 9 partidos, algo sem precedente na política brasileira. Tal dominância, como é de se esperar, se torna ainda mais expressiva quando se considera os ministérios de "coordenação", como o ministério do planejamento, da fazenda e da justiça.
Contudo, apesar da forte presença do partido do presidente, número expressivo de ministérios, inclusive ministérios mais importantes como o da saúde foram distribuídos aos partidos da base. Qual é o impacto de tal distribuição de cargos na estrutura do Executivo sobre a alocação de recursos? 0 presente trabalho busca identificar se existe relação entre a composição dos ministérios e a alocação de emendas parlamentares. Para tanto, primeiramente analisamos a importância relativa dos diferentes ministérios na engrenagem de alocação de emendas ao orçamento. 0 gráfico 1 apresenta o percentual de emendas por ministério. 
Gráfico 1. Total de Emendas por Ministérios (2004-2010)

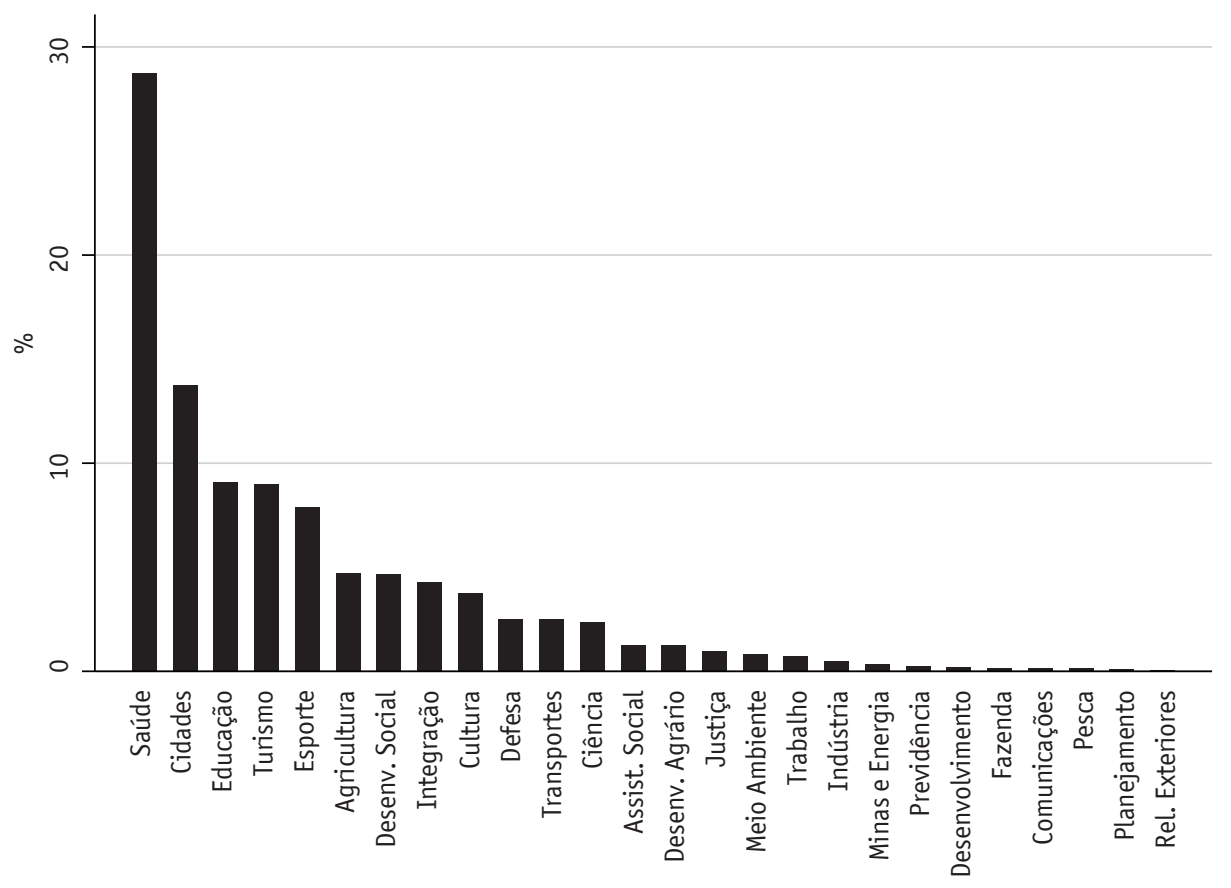

Fonte: elaboração própria.

0 gráfico 1 mostra o "destino" das emendas ao orçamento aprovadas pelos parlamentares brasileiros. Nota-se a importância do ministério da saúde como o principal alvo das emendas aprovadas. Ainda com participação expressiva estão os ministérios das cidades, educação, turismo, transportes, desenvolvimento social, agricultura e integração nacional. Estes ministérios correspondem ao destino da maioria das emendas e esta posição tem duas explicações: primeiro, saúde, educação e os ministérios que realizam obras como o de integração nacional são áreas de grande interesse para os parlamentares; segundo, esses são os ministérios com os maiores orçamentos de investimento e, portanto, orçamento disponível para a inclusão de emendas. Essa distribuição também é interessante pelo indicativo que oferece da diferença no peso e importância dos ministérios nesse aspecto específico das emendas parlamentares.

0 gráfico abaixo apresenta a relação entre o parlamentar e o ministro ao qual a emenda aprovada é vinculada.

Gráfico 2. Relação Parlamentar-Ministro na Execução das Emendas

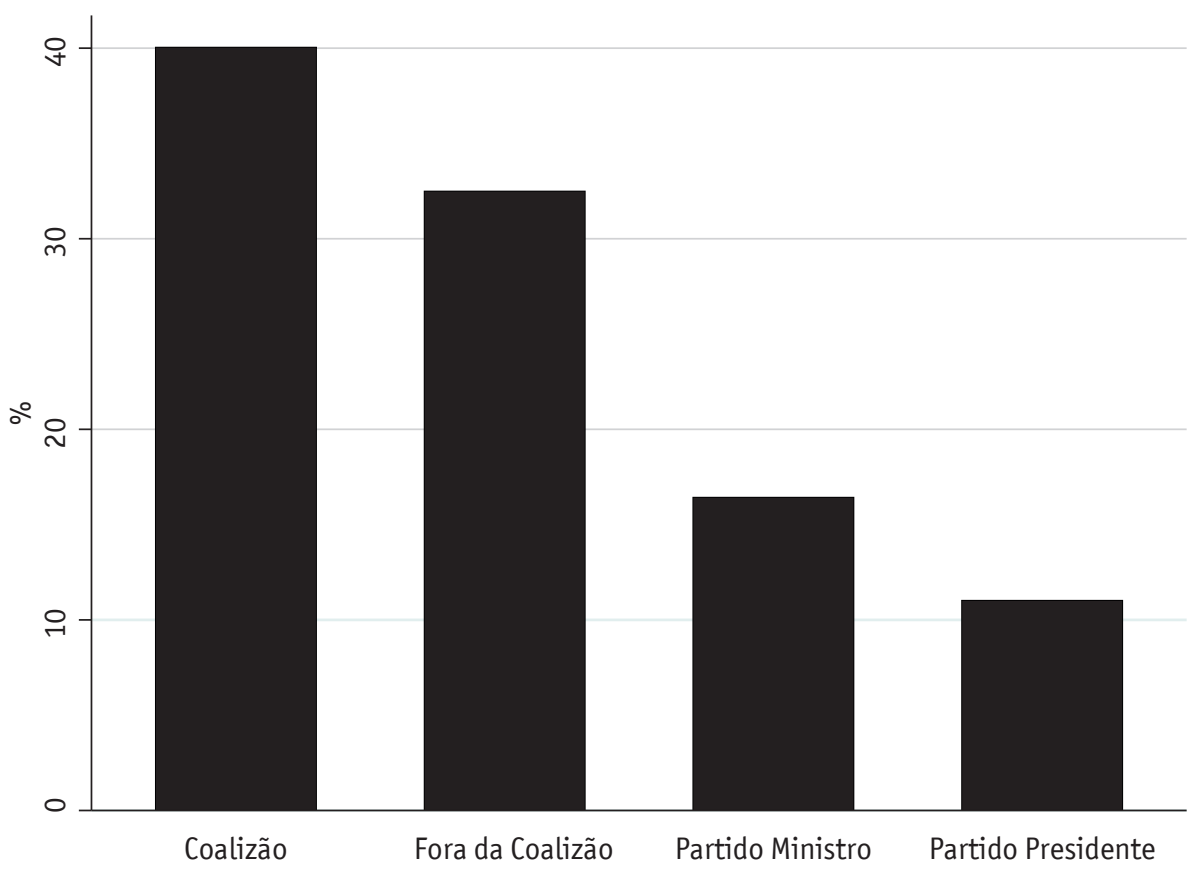


0 gráfico acima foca na relação entre o parlamentar e o ministro ao qual a emenda é vinculada. $40 \%$ das emendas aprovadas foram propostas por partidos membros da coalizão. Em seguida, 32,5\% das emendas foram propostas por partidos fora da coalizão governativa. Em 16,4\% dos casos as emendas foram enviadas por parlamentares para ministérios controlados pelo mesmo partido que o seu. Emendas propostas por membros do partido do presidente a ministérios controlados também pelo partido do presidente aconteceram em $11 \%$ dos casos. 0 objetivo aqui é identificar se ministros executam mais emendas do seu próprio partido ou mecanismos de coordenação impostos pela presidência, principalmente a partir da SRI minimizam a autonomia ministerial, mantendo as decisões do governo de acordo com as preferências do presidente.

Para tanto, será realizado um modelo de regressão logística que busca estimar a probabilidade de execução da emenda parlamentar, considerando como principal preditor a relação entre o parlamentar e o ministro. A variável independente será operacionalizada como um conjunto de variáveis dummy, na qual a categoria de referência é a situação "parlamentar e ministro são do mesmo partido". 0 objetivo é identificar se há um efeito diferencial de ser do mesmo partido do ministro sobre a chance de execução da emenda, comparando com as demais categorias: "partido da coalizão", "partido fora da coalizão" e "mesmo partido do presidente". Como controles serão incluídos efeitos fixos de ano e de ministério.

A variável dependente também se caracteriza como uma variável dummy, assumindo valor quando a emenda é executada e 0 na situação contrária. Duas especificações são usadas, uma para execução no período total e outra apenas para execução no exercício corrente (no ano vigente da lei orçamentária). A distribuição das variáveis dependentes são apresentadas abaixo.

Gráfico 3. Distribuição das Variáveis Dependentes - Execução da Emenda
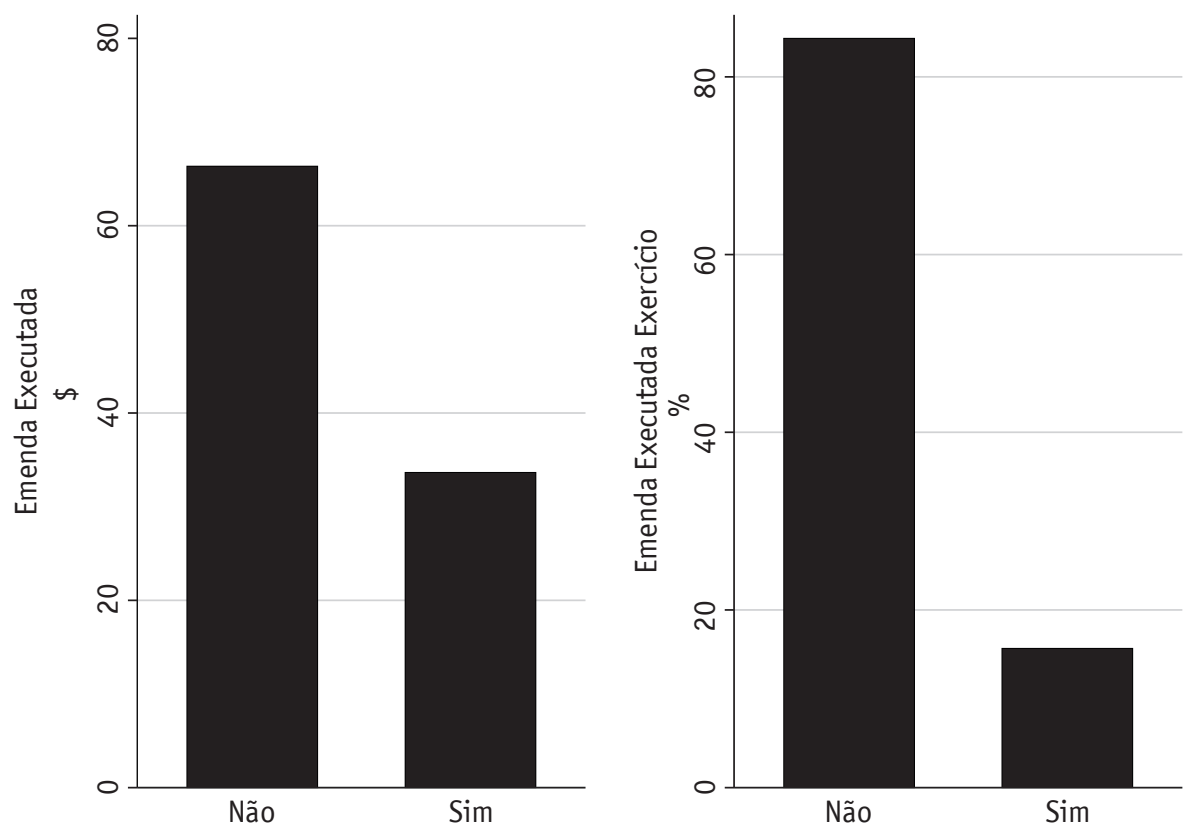

Fonte: elaboração própria.

0 painel esquerdo do gráfico apresenta a distribuição da execução total, mostrando que em torno de $66 \%$ das emendas parlamentares propostas ao orçamento e aprovadas não são efetivamente executadas. Essa proporção é ainda maior quando se considera a execução no exercício, apresentada no painel direito. Aqui $84 \%$ das emendas não são executadas. Isso quer dizer que aprovar a emenda não implica na sua execução. 0 orçamento é um recurso escasso e pelo desenho institucional brasileiro o Executivo tem a prerrogativa na alocação desses recursos. A questão passa a ser como o Executivo escolhe quais emendas serão priorizadas e quais serão ignoradas. Quem ganha e quem perde, quan- do e por que para parafrasear a clássica definição de política.

Considerando que o Executivo brasileiro não pode ser identificado exclusivamente com o presidente, sendo composto por diferentes partidos controlando os ministérios para os quais as emendas são enviadas, o objetivo é justamente identificar em que medida os ministros são capazes de usar a sua posição de decisão no governo para extrair rendas para o seu próprio partido. Espera-se que emendas enviadas por parlamentares do mesmo partido do ministro tenham maior probabilidade de execução. Os resultados para esse teste são apresentados na tabela a seguir. 
Tabela 2. Conexão Parlamentar-Ministro e Execução de Emendas ao Orçamento

\begin{tabular}{ccccc}
\hline & \multicolumn{2}{c}{ VD: Execução total } & \multicolumn{2}{c}{ VD: Execução Exercício } \\
\hline Modelo 1 & Modelo 2 & Modelo 3 & Modelo 4 \\
\hline Constante & $-.728^{* * *}$ & $.825^{* * *}$ & $-2.133^{* * *}$ & $-.506^{* * *}$ \\
& $(.022)$ & $(.053)$ & $(.033)$ & $(.077)$ \\
\hline Partido Presidente & -.022 & -.006 & $.087^{*}$ & $.148^{* *}$ \\
& $(.035)$ & $(.039)$ & $(.052)$ & $(.061)$ \\
\hline Partido Coalizão & $-.146^{* * *}$ & $-.130^{* * *}$ & $-.208^{* * *}$ & $-.104^{* * *}$ \\
\hline Partido Fora Coalizão & $(.026)$ & $(.028)$ & $(.041)$ & $(.044)$ \\
\hline Dummy Ano & $-.465^{* * *}$ & $-.469^{* *}$ & $-.608^{* * *}$ & $-.532^{* * *}$ \\
\hline Dummy Ministério & $(.028)$ & $(.030)$ & $(.045)$ & $(.049)$ \\
\hline Log Likelihood & Não & Sim & Não & Sim \\
\hline Lr Chi ${ }^{2}$ & Não & Sim & Não & Sim \\
\hline N & -33288.318 & -30915.886 & -16204.708 & -14555.308 \\
\hline
\end{tabular}

Coeficientes reportados. Erro padrão entre parênteses.

* Sig $0.10 ; *$ * Sig $0.05 ; * * *$ Sig 0.01 .

Os resultados acima mostra o efeito da relação entre o parlamentar e o ministro sobre a probabilidade de execução da emenda. "Mesmo partido do ministro" é a categoria de referência, de forma que a direção e efeito das demais categorias são sempre consideradas em relação aos parlamentares do mesmo partido do ministro. Os dois primeiros modelos analisam a execução total e os dois últimos a execução no mesmo exercício.

Nos dois primeiros modelos que tratam da execução total pode-se notar o sinal negativo em todas três categorias analisadas em referência aos parlamentares do mesmo partido do ministro. Isto é, comparando com parlamentares do mesmo partido do ministro, emendas propostas por parlamentares do mesmo partido do presidente, parlamentares de outros partidos da coalizão e parlamentares fora da coalizão tem menor probabilidade de execução. Contudo, esse resultado não é estatisticamente significativo para os parlamentares do mesmo partido do presidente, significando que não há diferença na probabilidade de execução da emenda para parlamentares do mesmo partido do ministro. Esse resultado se mantém incluindo controles do ano e de ministério. De forma geral esse resultado indica que há uma escala de prioridades na alocação de recursos pelo Executivo: primeiramente os parlamentares do mesmo partido que controla 0 ministério, os parlamentares do mesmo partido do presidente, os parlamentares dos demais partidos da coalizão e por último os parlamentares fora da coalizão de governo.

Os dois últimos modelos analisam a execução de emendas no exercício. A execução no exercício pode ser considerada como execução prioritária. São as emendas executadas primeiro num contexto de restrição orçamentária. Aqui a relação se altera um pouco. A probabilidade de execução das emendas de parlamentares do partido do presidente é maior do que dos parlamentares do mesmo partido do ministro, indicando que a prioridade é o partido do presidente. Para os demais membros da coalizão e para os partidos fora da coalizão a relação se mantém negativa e significativa.

Um comentário adicional sobre esse resultado é importante. 0 efeito negativo de estar fora do governo já é esperado e identificado na literatura. A execução de emendas é vista como uma forma de recompensar os parlamentares pelo apoio político e estar fora da coalizão anuncia a exclusão desses benefícios. Contudo, não foi ainda explorado como a engrenagem funciona no sentido de executar as emendas dos partidos da coalizão. A escala de prioridades mostrada acima indica que o ministro prioriza primeiro o seu próprio partido e o partido do presidente, em seguida os demais partidos da coalizão e em último lugar os partidos fora da coalizão. Os quatro modelos são significativos como um todo como indicado pelo $\mathrm{Lr} \mathrm{Chi}^{2}$. Quanto ao total de observações analisadas na regressão, a diferença se dá devido ao fato de que para 13.698 emendas não foi possível estabelecer a relação entre o parlamentar e o ministro, seja por se tratar de emendas de bancada ou por não indicar o partido do parlamentar. Dessa forma, o número de observações total para a análise de regressão foi de 56.254 emendas. Como os coeficientes da regressão logística não estão transformados, a sua interpretação substantiva é feita com base nos gráficos apresentados abaixo. 
Gráfico 4. Conexão Parlamentar-Ministro e Probabilidade de Execução (95\% I.C.)

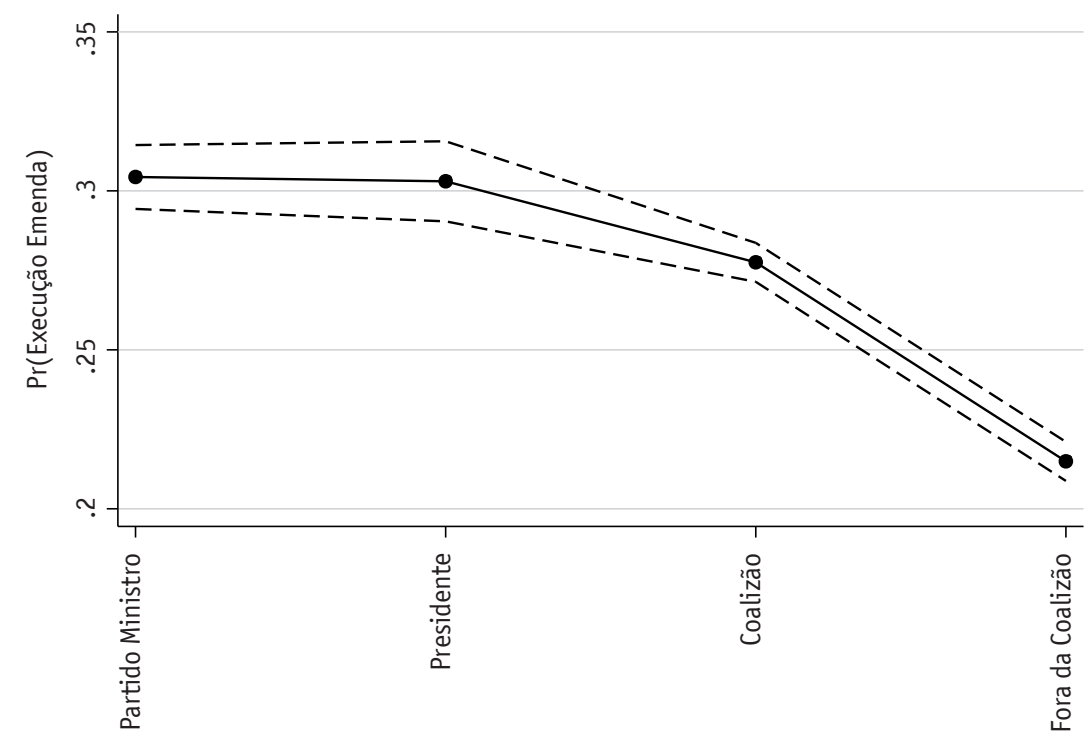

Fonte: elaboração própria.

0 gráfico acima mostra a escala de prioridades na execução de emendas parlamentares ao orçamento, dependendo da relação do parlamentar com o ministro ao qual a emenda está vinculada. 0 gráfico mostra que não há diferença estatística entre a probabilidade de execução de emendas do mesmo partido do ministro e emendas de parlamentares do partido do presidente. A probabilidade de execução é 0.30 . Quando se trata de emendas dos demais partidos da coalizão essa probabilidade já cai para 0.27 . Por último, a probabilidade de execução de emendas de parlamentares fora da coalizão é de 0.21. 0 gráfico 4 apresenta a probabilidade de execução no exercício.

Gráfico 4. Conexão Parlamentar-Ministro e Probabilidade de Execução no Exercício (95\% I.C.)

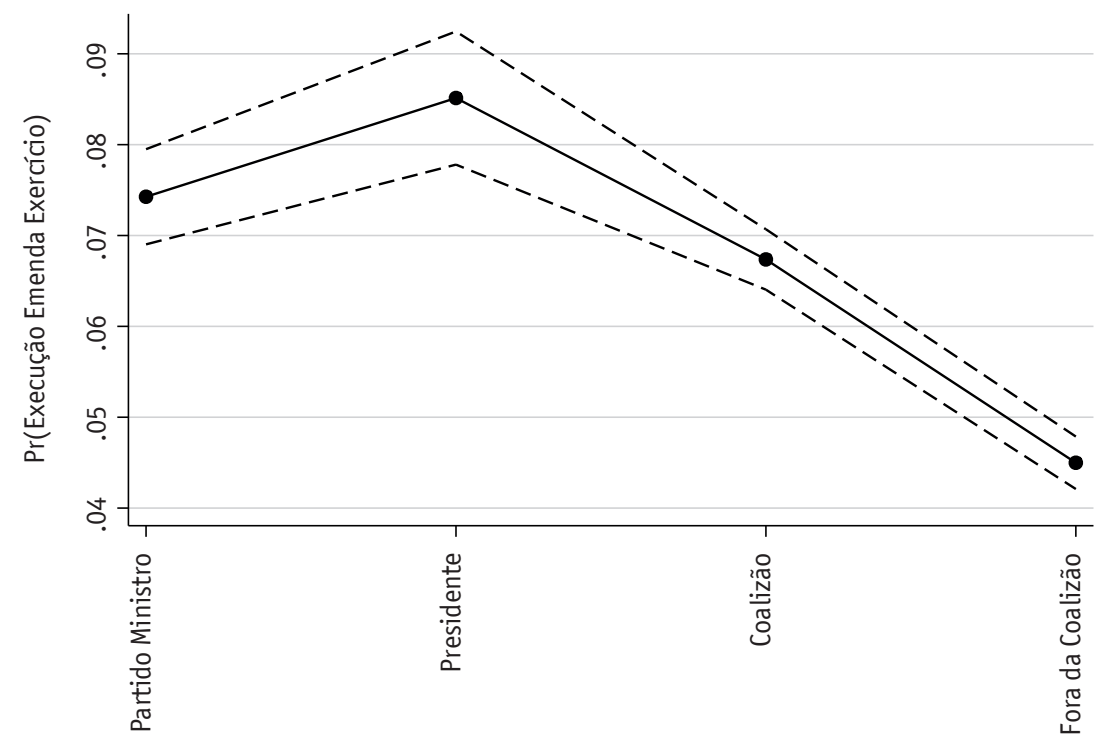

Fonte: elaboração própria.

Em geral a probabilidade de execução no exercício é muito baixa. Porém,, há diferenças entre os parlamentares na prioridade de execução. Primeiramente estão os parlamentares do mesmo partido do presidente (0.085), seguidos por parlamentares do mesmo partido do ministro (0.075), depois os parlamentares dos demais partidos da coalizão (0.068) e por último os partidos fora da coalizão (0.042).
Três resultados principais podem ser derivados dessa análise. Primeiro, controlar um ministério pode ser um instrumento fundamental para garantir acesso as decisões do Executivo, incluindo a execução de emendas parlamentares. 0 efeito negativo de estar fora do governo já é esperado e identificado na literatura. A execução de emendas é vista como uma forma de recompensar os 
parlamentares pelo apoio político e estar fora da coalizão anuncia a exclusão desses benefícios. A escala de prioridades mostrada acima indica que o ministro prioriza primeiro o seu próprio partido e o partido do presidente, em seguida os demais partidos da coalizão e em último lugar os partidos fora da coalizão.

Segundo, o fato de os ministros não serem capazes de beneficiar mais o seu partido do que o partido do presidente ou excluir totalmente os demais partidos da coalizão mostram a efetividade dos mecanismos de coordenação da coalizões instituídos na Presidência da República, principalmente através da Secretaria de Relações Institucionais que recebe as demandas dos parlamentares e monitora os ministros para que os interesses do presidente sejam mantidos.

Terceiro o efeito da relação com o ministro é pequeno quando se considera a mudança na probabilidade de execução. Isso indica que características do parlamentar como a disciplina partidária ou do estado ao qual a emenda é destinado, características já analisadas pela literatura e que não se constituem no foco da presente análise, podem ser mais importantes quando o que está e jogo é a execução de emendas. 0 resultado aqui apresenta não deixa de ser relevante uma vez que aponta para mais um dos fatores a influenciar a alocação de recursos e indica a influência dos ministros no processo decisório do presidencialismo de coalizão brasileiro.

\section{Conclusão}

0 presente trabalho teve por objetivo principal analisar o papel dos ministros na alocação de recursos pelo Poder Executivo federal. 0 foco está nas emendas parlamentares ao orçamento, avaliando em que medida os ministros se configuram como um canal privilegiado para os membros do seu partido no Congresso através da análise da execução das emendas por ministério. Há um viés partidário na alocação de recursos? Isto é, as emendas dos parlamentares do partido do ministro são beneficiados com maior chance de execução de suas emendas?

Os resultados sugerem que os parlamentares do partido do ministro são sim beneficiados. Contudo, o “governo ministerial" (Laver e Shepsle, 1990) não se impõe e os parlamentares do partido do presidente são igualmente beneficiados e os parlamentares dos demais partidos da coalizão também recebem recursos. Nesse sentido, as instituições de coordenação do governo, principalmente a SRI, atuam no sentido de minimizar os efeitos negativos da autonomia ministerial e garantir um resultado mais próximo das preferências do presidente.

\section{Referências Bibliográficas}

ALSTON, Lee; MELO, Marcus; MULLER, Bernardo; PEREIRA, Carlos (2009). “Presidential Power, Fiscal Responsibility Laws, and the Allocation of Spending: The Case of Brazil". In: HALLERBERG, Mark; SCARTASCINI, Carlos; STEIN, Ernesto: Who Decides the Budget: a political economy analysis of the budget process in Latin America. Inter-American Development Bank.

AMORIM NETO, Octávio (2006). Presidencialismo e Governabilidade nas Américas. Editora Fgv: Rio de Janeiro.

BERRY, Christopher; BURDEN, Barry; HOWELL, Howell (2010). "The President and the Distribution of Federal Spending." American Political Science Review, v. 104.

BUDGE, Ian; LAVER, Michael (1986). “Office Seeking and Policy Pursuit in Coalition Theory”. Legislative Studies Quarterly, Vol. 11, No. 4.

CHEIBUB, José Antônio; PRZEWORSKI, Adam; SAIEGH, Sebastian (2002). “Governos de Coalizão nas Democracias Presidencialistas e Parlamentaristas". Dados, 45, 2.

DE SWAAN, Abram (1973). Coalition Theories and Cabinet Formation. Amsterdam: Elsevier.

EDWARDS III, George; KESSEL, John; ROCKMAN, BERT (EDs) (1993). Researching the Presidency: vital questions, new approaches. University of Pittsburgh Press: Pittsburgh.

FIGUEIRED0, Argelina; LIMONGI, Fernando (2001). Executivo e Legislativo na Nova Ordem Constitucional. Editora FGV: Rio de Janeiro.

FIGUEIRED0, Argelina; LIMONGI, Fernando (2008). Política Orçamentária e Presidencialismo de Coalizão. Editora FGV: Rio de Janeiro.

FIGUEIRED0, Argelina (2007). "Governments Coalitions in Brazilian Democracies". Brazilian Journal of Political Science, v. 1, n. 2.

GAMSON, William (1961). "A Theory of Coalition Formation". American Sociological Review, v. 26, n. 3.

INÁCIO, Magna (2006). “Entre Presidir e Coordenar: presidência e gabinetes multipartidários no Brasil". Paper preparado para apresentação no 3 Encontro Latino-americano de Ciência Política. Campinas - Brasil.

LAVER, Michael; SHEPSLE, Kenneth (1990). "Coalitions and Cabinet Government". American Political Science Review, v. 84, n. 3.

LAVER, Michael; SHEPSLE, Kenneth (1994). Cabinet Ministers and Parliamentary Government. Cambridge University Press: Cambridge.

MARTIN, Lanny; VANBERG, Georg (2011) Parliaments and Coalitions: The Role of Legislative Institutions in Multiparty Governance. 0xford: 0xford University Press.

MOE, Terry (1985). “The Politicized Press". In. John E. Chubb \& Paul E. Peterson: The New Directions in American Politics. The Bookings Institution: Washington. 
MULLER, Wolfgang; STROM, Kaare (1999). Policy, Office or Votes: how political parties in Western Europe make hard decisions". Cambridge: Cambridge University Press.

MULLER, Wolfgang; STROM, Kaare (2000). Coalition Governments in Western Europe. 0xford University Press: 0xford. NEUSTADT, Richard (1961). Presidential Power: the politics of leadership. John Wiley \& Sons: New York - London.

PEREIRA, Carlos; RENNÓ, Lúcio (2001). “0 que é que o Reeleito Tem? Dinâmicas Político-Institucionais Locais e Nacionais nas Eleições de 1998 para a Câmara dos Deputados". Dados, V. 44, N. 2.

PEREIRA, Carlos; MULLER, Bernardo (2003). “Partidos fracos na arena eleitoral e partidos fortes na arena legislativa: a conexão eleitoral no Brasil". Dados, V. 46, N. 4.

PEREIRA, Carlos; MULLER, Bernardo (2003). “The cost of governing: strategic behavior in Brazil's budgetary process". Textos para Discussão, N. 304, Universidade de Brasília.

RAILE, Eric; PEREIRA, Carlos; POWER, Timothy (2010). "Executive Toolbox: building legislative support in a multiparty presidential regime". Textos para discussão, N. 235, Escola de Economia de São Paulo.

RUDALEVIGE, Andrew (2002). Managing the President's Program: presidential leadership and legislative policy formulation. Princeton University Press: New Jersey.

RUDALEVIGE, Andrew; LEWIS, David (2005). “Parsing the Politicized Presidency: centralization and politicization as presidential strategies for bureaucratic control". Paper prepared for presentation at the 2005 Annual Meeting of the American Political Science Association, Washington, DC.

THIES, Michael (2001). "Keeping tabs on partners: the logic of delegation in coalition governments", American Journal of Political Science, v. 45, n. 3.

\section{Notas}

1 Versão anterior desse trabalho foi apresentado no $36^{\circ}$ Encontro Anual da Anpocs, no Grupo de Trabalho “Estudos Legislativos". Agradeço aos pertinentes comentários do coordenador do Gt Gustavo Grohmann. Agradeço ainda a Fernando Ramalho do Senado Federal pela atenção e paciência na ajuda com os dados das emendas parlamentares ao orçamento. Agradeço ainda a Argelina Figueiredo pela disponibilização de seu banco de dados sobre os ministros brasileiros e a Ana Regina Amaral, da Câmara dos Deputados, pelas inúmeras dúvidas respondidas. Qualquer imprecisão remanescente é de minha total responsabilidade.

* Mestre e doutora em Ciência Política pela Universidade Federal de Pernambuco. Professora Adjunta do Departamento de Ciência Política da mesma instituição. Pesquisa nas áreas de Poder Executivo e Governos de Coalizão, Agências Reguladoras, Corrupção e Metodologia Política. Trabalhos publicados em Revista Brasileira de Ciências Sociais, Opinião Pública e Brazilian Political Science Review. mariana.bsilva@gmail.com 